Asian Pacific Journal of Reproduction

Journal homepage: www.apjr.net

\title{
Impact of electromagnetic radiation exposure during pregnancy on embryonic skeletal development in rats
}

\author{
Ali SAEED H Alchalabi ${ }^{1,2 \bowtie}$, Erkihun Aklilu ${ }^{1}$, Abd Rahman Aziz ${ }^{1}$, Hasliza Rahim ${ }^{3}$, Suzanna H Ronald ${ }^{3}$, Mohd F \\ Malek $^{4}$, Mohd Azam Khan ${ }^{1}$ \\ ${ }^{1}$ Faculty of Veterinary Medicine, UMK City Campus, Pengkalan Chepa, Locked Bag36, 16100 Kota Bharu, Kelantan, Malaysia \\ ${ }^{2}$ Veterinary Medicine College, Mosul University, Mosul, Iraq \\ ${ }^{3}$ School of Electrical System Engineering, University Malaysia Perlis (UniMAP), Pauh Putra, 02600 Arau, Perlis, Malaysia \\ ${ }^{4}$ University of Wollongong, Dubai, United Arab Emirates
}

\section{ARTICLE INFO}

Article history:

Received 6 February 2017

Revision 2 March 2017

Accepted 16 March 2017

Available online 1 May 2017

Keywords:

GSM electromagnetic radiation

Embryonic development

Bone turnover processes

Pregnant rats

\begin{abstract}
Objective: To evaluate the teratogenic effect of mobile phone radiation exposure during pregnancy on embryonic skeletal development at the common used mobile phone frequency in our environment. Methods: Sixty female Sprague-Dawley rats were distributed into three experiment groups; control and two exposed groups ( $1 \mathrm{~h} / \mathrm{day}, 2 \mathrm{~h} /$ day exposure groups) ( $n=20$ / each group) and exposed to whole body radiation during gestation period from day 1- day 20. Electromagnetic radiofrequency signal generator was used to generate $1800 \mathrm{MHz}$ GSM-like signals at specific absorption rate value $0.974 \mathrm{~W} / \mathrm{kg}$. Animals were exposed during experiment in an especial designed Plexiglas box $(60 \mathrm{~cm} \times 40 \mathrm{~cm} \times 30 \mathrm{~cm})$. At the end of exposure duration at day 20 of pregnancy animals were sacrificed and foetuses were removed, washed with normal saline and processed to Alizarin red and Alcian blue stain. Skeleton specimens were examined under a stereo microscope and skeleton's snaps were being carefully captured by built in camera fixed on the stereo microscope. Results: Intrauterine exposure to electromagnetic radiation lead to variation in degree of ossification, mineralization, formation of certain parts of the skeleton majorly in head and lesser in other parts. Deformity and absence of formation of certain bones in the head, ribs, and coccygeal vertebrae were recorded in skeleton of foetuses from exposed dams compare to control group. Conclusions: The electromagnetic radiation exposure during pregnancy alter the processes of bone mineralization and the intensity of bone turnover processes, and thus impact embryonic skeleton formation and development directly.
\end{abstract}

\section{Introduction}

Nowadays, most human environments are immersed in a sea of huge amounts of electromagnetic waves. These electromagnetic waves have two principal roots, natural sources and man-made sources. Mobile phones and base stations, video and radio broadcasting facilities, radar, medical equipment, microwave ovens and radio frequency heaters as well as a diverse variety of other electronic devices, are just a few examples within our living and shaping environments[1-3]. The two influence body world systems,

Corresponding author: Ali SAEED H Alchalabi, Faculty of Veterinary Medicine, UMK City Campus, Pengkalan Chepa, Locked Bag36, 16100 Kota Bharu, Kelantan, Malaysia.

Tel: +60112947731

E-mail: alisaeedchalaby@yahoo.com
International Commission on Non-Ionizing Radiation Protection and the World Health Organization are concerned with the bioeffects of electromagnetic field (EMF) in terms of biological health effects of RFR on human; they do not comprise pregnant women and their infants[4]. Juveniles also have some priority through animal works focusing on the early-life and prenatal effect due to exposure to radiofrequency electromagnetic fields (RF-EMFs).

This is an open access article distributed under the terms of the Creative Common Attribution-Non Commercial-Share Alike 3.0 License, which allows others to remix, tweak and buid upon the work non-commercially, as long as the author is credited and the new creations are licensed under the identical terms.

For reprints contact: reprints@medknow.com

C2017 Asian Pacific Journal of Reproduction Produced by Wolters Kluwer- Medknow

How to cite this article: Ali SAEED H Alchalabi, Erkihun Aklilu, Abd Rahman Aziz, Hasliza Rahim, Suzanna H Ronald, Mohd F Malek, Mohd Azam Khan. Impact of electromagnetic radiation exposure during pregnancy on embryonic skeletal development in rats. Asian Pac J Reprod 2017; 6(3): 104-111. 
Although in the research agenda for radiofrequency fields, the World Health Organization in section animal studies put "In vivo studies on fertility should consider effects on both males and females and investigate a range of relevant endpoints, including RF EMF effects of the development and function of the endocrine system" as other research requirements, but still this is important to highlight the most potential effects of RF on pregnant animals[5]. A study conducted by Berman et al.[6] reported that RF-EMF exposure at $2450-\mathrm{MHz}$ microwave radiation up to $100 \mathrm{~min} /$ day during pregnancy has no potential effect on the gross structure of the foetal rat and there are no incidences of external, visceral, or skeletal anomalies or variations; alternatively, in the body weight of live fetuses. In 1982, A study by Lary et al.[7] on rats to investigate the teratogenic effect of 27.12 $\mathrm{MHz} \mathrm{RF}$ radiation exposure during a pregnancy period. The authors stated that RF induced preimplantation malformations, foetal weight and crown rump length reduction in post-implantation exposure groups. Chick embryos were exposed to a standard mobile phone hand operate with a frequency of $900 \mathrm{MHz}$, specific absorption rate (SAR) of $0.37 \mathrm{~W} / \mathrm{Kg}$ was calculated in an exposed embryo. In this study, the authors were reported that cellular phone radiation led to observable kidney damage in developing embryo, which was more extensive with longer duration of exposure, and this kind of damage was irreversible even after discontinuing the exposure[8]. Two separated studies during two different periods in 2009 and 2011, investigated the effect of commercial mobile phone's potential effect of foetal embryonic development[9,10]. Both of them indicated that cell phone radiation at $900 \mathrm{MHz}$ can induce detrimental effect on embryonic development in both mice and rats through its effect on skeletal formation development. Irradiated chick embryos during incubation periods with commercial cellular phone operated with (900 MHz-1 $800 \mathrm{MHz}$ ) frequency showed malformed embryonic eye growth till 10 days of incubation which affect negatively on brain development causing brain malformation[11]. Pregnant mice exposed to $950 \mathrm{MHz}$ at $\mathrm{SAR}=1 \mathrm{~W} / \mathrm{kg}$ and $1800 \mathrm{MHz}$ at SAR=1.6 $\mathrm{W} / \mathrm{kg}$ respectively from day 7 to day 14 of gestation for $2 \mathrm{~h} /$ day[12]. The author did not reported any morphological abnormalities but he observed histopathological changes in embryonic retinal tissue represented by pyknotic nuclei in both outer and inner nuclear layers. Furthermore, mice exposed in-utero to 800-1 $900 \mathrm{MHz}$ cellular phone with a SAR of $1.6 \mathrm{~W} / \mathrm{kg}$ placed over the feeding bottle area at a distance of $4.50-22.3 \mathrm{~cm}$ from the mice, exhibited neuropathology due to in-utero RF radiation[13].

On other hand, Sambucci et al.[14] found that prenatal exposure to Wi-Fi signals during gestation did not exhibited any bad effect on pregnancy outcome. A study in 2013 by Poulletier de Gannes et al.[15], did not indicate any potential effects due to in-utero WiFi signals exposure at average $1 \mathrm{~h}$ /day even at high SAR levels 4 $\mathrm{W} / \mathrm{kg}$. In addition to that the study proved that $2.45 \mathrm{GHz}$ had no macroscopic abnormalities effect in fetuses exposed in-utero.

These kinds of controversial results put the researches on the seriousness of the exposed pregnant mothers to RF radiation and its impact on embryonal development. The aim of this study is to investigate the gene expression of Msx 1 and Cx43 and the teratogenic effect in prenatal foetuses of Sprague-Dawley rats.

\section{Materials and methods}

\subsection{Animals}

Healthy, young female Sprague-Dawley rats (three months old) from Animal Research and Service Centre, Universiti Malaysia Kelantan was employed in this study. Rats were kept quarantined in animal breeding and research unit in the faculty perubatan veterinar/ Universiti Malaysia Kelantan for two weeks to monitor their wellness and to acclimatize in the new research lab environment. Animal were kept in the breeding cages $(44 \mathrm{~cm} \times 34 \mathrm{~cm} \times 20 \mathrm{~cm})$ under the same breeding condition at room temperature $(24 \pm 100){ }^{\circ} \mathrm{C}$ and humidity $(60 \% \pm 10 \%)$ relative humidity with light/ dark cycle 12 $12 \mathrm{~h}$ (photo period), tap water and standard rat pellet were provided ad libitum. Animal were mate with male rats, presence of vaginal plug and sperms in the vaginal smear used as indicator of day one of pregnancy. Sixty animals were distributed into three experiment groups ( $n=20$ / each group); control and two exposed groups $(1 \mathrm{~h} /$ day, $2 \mathrm{~h}$ /day exposure groups). during the experiment time under exposure conditions, animals were retained in an especial designed Plexiglas box $(60 \mathrm{~cm} \times 40 \mathrm{~cm} \times 30 \mathrm{~cm})$ with ventilation holes on the cover $3 \mathrm{~cm}$ in diameter. Ethics recommendations of animal welfare were carried out to the experimental animals during gentle handling and experimentation. The experimental protocols were reviewed and sanctioned by the scientific committee of faculty veterinary medicine.

\subsection{Global system for mobile communications (GSM) exposure setup}

The RF-EMR exposure system Global System for Mobile Communications used for this study to provide 1800 MH GSMlike frequency. The system was composed of the PSG vector signal generators (Agilent Technologies E8267D, 250 KHz-20 GHz, Santa Clara, CA USA) with the integrated pulse modulation unit. Signal source of the mobile phone antenna was a standard horn antenna (A-INFORMW Standard Gain Horn Antenna 1.7-2.6 GHz WR430, China). The experiment was carried out in unshielded room in the experimental research unit. RF signal generator connected by a low loss coaxial cable $(3 \mathrm{~m})$, and the distance between RF generator and antenna are three metres. Spectrum analyzer (R\&S®FSH4, 9 KHz-3.6 GHz, Rohde \& Schwartz GmbH \& Co.kg. Germany) was used to control the generator power and integrated to the signal generator. The signals were amplitude-modulated by rectangular pulses with pulse width 0.576 milliseconds (repetition frequency of $217 \mathrm{~Hz}$ and duty cycle of 1:8), corresponding to the dominant modulation component of the GSM. The signal generator pumped $20 \mathrm{dBm}$ power $(0.1 \mathrm{~W})$ during the experiment period, and a basic electromagnetic radiation detector (DT-1130, China) was used to confirm that the signal is currently radiating[4,16-18]. 


\subsection{Sampling}

Experimented pregnant females were euthanized at GD 20 (one day before normal delivery), and the fetuses were removed an outside uterus by caesarean sections. Fetuses were washed by $37{ }^{\circ} \mathrm{C}$ normal saline $0.9 \%$ to clean them from uterine fluid and blood. Skeletal system abnormalities in fetuses/group using staining Alizarin red and Alcian blue stains was applied.

\subsubsection{Skeleton preparation and staining}

Randomly selected $50 \%$ of total fetuses/group for investigating the skeletal abnormalities using visualization of the skeletal system staining Alizarin Red and Alcian Blue. The process of visualization pass through three processes; fixation, staining and clearing process[19,20].

The skeletal system staining protocol was run as follows: (A) Fixation process: rat fetuses were skinned carefully and eviscerated completely and fixed at room temperature in $95 \%$ ethanol for two weeks. Pure acetone was applied to get rid of the fatty tissue from the fetuses after fixation steps with ethanol and fetuses were kept in acetone for $24 \mathrm{~h}$ at room temperature. (B) Staining process: in this step, stain was prepared as follows: (1) $0.1 \%$ of Alizarin red-S in $95 \%$ ethanol ( $250 \mathrm{mg}$ dissolved in $250 \mathrm{~mL} \mathrm{95 \%} \mathrm{ethanol);} \mathrm{(2)}$ $0.3 \%$ of Alcian blue in $70 \%$ ethanol $(750 \mathrm{mg}$ dissolved in $250 \mathrm{~mL}$ $70 \%$ ethanol); (3) Glacial acetic acid (250 mL); (4) Ethanol 70\% (4250 mL).

About $0.1 \%$ Alizarin red-S stain was added to $0.3 \%$ Alcian blue, plus glacial acetic acid carefully. The final volume was completed to $5 \mathrm{~L}$ by $70 \%$ ethanol and kept in at room temperature until used. Fixed fetuses were transferred to staining jar and the staining step was carried at $40{ }^{\circ} \mathrm{C}$ for one week, fetuses after that washed from stain by tap water up to three hours and transferred to the clearing operation.

(C) Digestion and clearing process. In this step, fetuses were transferred to a jar containing $2 \% \mathrm{KOH}$ solution for $48 \mathrm{~h}$, after that fetuses were put in aqueous solution of $20 \%$ glycerine plus $1 \%$ $\mathrm{KOH}$ and left until the skeleton becomes clearly visible. Skeletons were transferred to jar contain 1:1 glycerine: $95 \%$ ethanol solution for $24 \mathrm{~h}$ at room temperature. Skeletons were passed through two concentrations of glycerine/ ethanol solutions, $50 \%$ and $80 \%$ for each concentration one-week point. Last step through this process was storing the skeletons in $100 \%$ glycerine containing mold growth inhibitor (few thymol crystals). Skeleton specimens were examined under a stereo microscope (Olympus SZX 2-ILIT, Olympus Corporation, Tokyo, Japan). Skeleton's snaps were being carefully captured by built in camera (Olympus DP71 cooled digital camera) fixed on the stereo microscope.

\section{Results}

3.1. Effect of $1800 \mathrm{MHz}$ GSM on embryonic skeletal formation and development

Inspection of the stained foetal skeleton for detection of skeletal deformities was performed on all body regions (head, thoracic, vertebrae, pelvis and limbs). Cranial bones, pectoral cage ribs, pectoral and coccygeal vertebrae, humorous, radius, ulna, carpus, Os coxae, femur, tibia and fibula displayed some developmental variations in the $1 \mathrm{~h} /$ day and $2 \mathrm{~h} /$ day exposure groups compared to the control group (Figure 1). Table 1 shows the descriptive differences between irradiated and control foetuses according to the body regions.

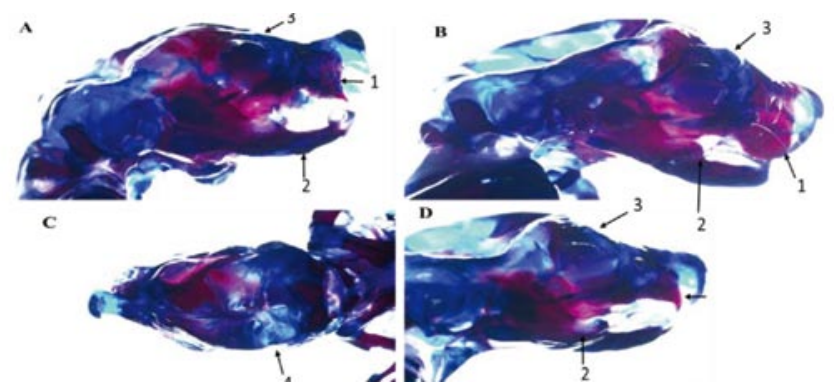

Figure 1. Cranium of experimented foetal skeleton at GD 20.

(A) Control skeleton cranium shows normal bone formation and ossification. (B) Cranium of 1h/day exposure to GSM-like signals show anomalies in premaxilla and mandible bones indicated by $(1,2)$ and less ossification in frontal bone indicated by (3). (C) Cranium of $1 \mathrm{~h} /$ day group show unossified bones of the skull in parietal bone indicated by (4). (D) Cranium of $2 \mathrm{~h}$ /day exposure to GSM-like signals show fragmentation on premaxilla and mandible bones with incomplete differentiation $(1,2)$ and less ossification (3).

The degree of mineralization varied within different parts of the body, a Pearson Chi-square test was employed to assess the difference of mineralization degree in the foetal skeleton within experimental groups. For the head and limbs regions, the mineralization percentage was significantly lower in the foetal skeleton of the exposed group than the control ones at $P$ value 0.018 in head region and $P$ value 0.03 in limbs. While there are irrelevant differences within thorax, vertebrae and pelvis regions. Furthermore, the mineralization degree in thoracic and vertebral regions shows irrelevant differences between exposed and control groups with $P$ values 0.541 , and 0.425 , respectively.

Fragmentation of bones is another parameter used to evaluate the bone development. Pelvis and limb bones of intrauterine exposed foetuses showed high significant differences in degree of fragmentation compared to control ones (Chi-square values 18.999, 27.971) at $P$ values 0.000 for both pelvis and limb bones. While head bones did not show any differences between experimented groups 
Table 1

Effect of RF-EMF on foetal skeleton development (descriptive study).

\begin{tabular}{|c|c|c|c|}
\hline Parameters & Control & $1 \mathrm{~h} /$ day exposure & $2 \mathrm{~h} /$ day exposure \\
\hline Head & $\begin{array}{l}\text { Well distributed mineralization pattern } \\
\text { of the skull with bone and cartilages } \\
\text { Well-formed bulbar soft-palate with } \\
\text { straight connection between rostral and } \\
\text { caudal aspects } \\
\text { Curved rostral aspects of the maxilla and } \\
\text { mandible } \\
\text { Temporomandibular joint (TMJ) } \\
\text { mineralization well formed } \\
\text { No cricoid cartilage checked on VD } \\
\text { Occipital protuberance well formed }\end{array}$ & $\begin{array}{l}\text { Remarkable mineralization of the skull. } \\
\text { High bone to cartilage ratio } \\
\text { Spindle-shaped soft-palate with straight } \\
\text { connections between the rostral and } \\
\text { caudal aspects } \\
\text { Relatively linear rostral aspects of the } \\
\text { maxilla and mandible } \\
\text { TMJ not well formed } \\
\text { Well-formed cricoid cartilage } \\
\text { Occipital protuberance well formed }\end{array}$ & $\begin{array}{l}\text { Occipital protuberance well formed } \\
\text { Spindle-shaped soft-palate with a kinked } \\
\text { connection between the rostral and } \\
\text { caudal aspects } \\
\text { Relatively linear rostral aspects of the } \\
\text { maxilla and mandible } \\
\text { TMJ remarkably ill formed } \\
\text { Distorted cricoid cartilage } \\
\text { Distorted formation of the occipital } \\
\text { protuberance }\end{array}$ \\
\hline $\begin{array}{l}\text { Thoracic \& Vertebral column } \\
\text { Thoracic vertebrae } \\
\text { Coccygeal vertebrae }\end{array}$ & $\begin{array}{l}\text { Well-formed thoracic vertebrae with } \\
\text { bulbar rib head attachment and well } \\
\text { distributed mineralization of the bones } \\
\text { Advanced development of the coccygeal } \\
\text { vertebrae with distinct processes from } \\
\text { the } 1 \text { st coccyx to the } 9 \text { th } \\
\text { Non-extensive mineralization of the } \\
\text { vertebrae } \\
\text { Absence of the coccyx at the mid- } \\
\text { segment while light to dark-stained } \\
\text { immature vertebrae are seen on the tail } \\
\text { tips }\end{array}$ & $\begin{array}{l}\text { Remarkable mineralization of the } \\
\text { vertebrae with less bulbar rib head } \\
\text { attachment } \\
\text { Advanced formation of the coccygeal } \\
\text { vertebrae from the 1st coccyx to the } 8 \text { th } \\
\text { with distinct processes } \\
\text { Mineralization is observable at the } \\
\text { dorsal and lateral aspects of the last three } \\
\text { coccyx } \\
\text { Complete absence of vertebrae from the } \\
9 \text { th onwards (to the tip to the tail) } \\
\text { Tail length is remarkably shortened and } \\
\text { stubby in comparison to the control }\end{array}$ & $\begin{array}{l}\text { Closely similar to } 1 \mathrm{~h} \text { P.E with decreased } \\
\text { stain pick up by the bones in comparison } \\
\text { with the control and } 1 \mathrm{~h} / \text { day exposure } \\
\text { Advanced formation of the coccygeal } \\
\text { vertebrae from the } 1 \mathrm{st} \text { to the } 7 \text { th with } \\
\text { distinct processes } \\
\text { Extensive mineralization of the early } \\
\text { vertebrae at the dorsum } \\
\text { Stubby and short tail coupled with } \\
\text { complete absence of coccygeal bones } \\
\text { throughout the length of the tail from the } \\
7 \text { th coccyx }\end{array}$ \\
\hline
\end{tabular}

Scapula Adequately formed scapula $\quad$ Adequately formed scapula

Adequately formed scapula with slight difference (increase) in bone to a cartilage ratio

Thoracic, forelimbs \& Vertebral Sparse mineralization of the rib at a level Closely similar mineralization pattern of Increased mineralization across the column proximal to the costochondral junction

the ribs as the control group, except for length of the rib

widening at the costochondral junction Sparse cartilage formation (demineralization) itself and diffused demineralization that increases from 1st to the 9th rib (cartilage) on the fifth rib

Widening of the ribs at the level of the costochondral junction Irregular borders of the ribs (bulging)

Humerus

Radius and Ulna

Os coxae

Femur

Carpus

Tibia \& Fibula
Distinct proximal epiphyseal plate Indistinct proximal epiphyseal plate. Slightly discernible epiphyseal plate. margin Partial loss of mineralized trabeculae in Partial loss of mineralized trabeculae in Uniform mineralized trabecular pattern the mid-diaphysis region on the physis

Uniform mineralization of both radius Non-uniform mineralization of the Non-uniform mineralization but wel and ulna and regular borders radius and ulna with loss of cortical distributed pattern in comparison with The ulna proximal epiphyseal plate is strength (demineralized trabeculae and $1 \mathrm{~h} /$ day exposure. Central loss of bone distinct fissures-fragmentation-occurring in the tissue in the mid-diaphysis as well as mid-diaphysis) mid-diaphyseal fragmentation of the radius

Irregular borders and bulging of the bones

Well formed

Larger obturator foramen

Fragmentation of the iliac body Irregular ischial body

Femoral head well attached to the Larger obturator foramen acetabulum Fragmentation of the iliac body Osteochondral lines are clearly Irregular iliac crest

Femoral head well attached to the Sacrum in process of union acetabulum acetabulum Osteochondral lines are less clearly Osteochondral lines are clearly discernible discernible Sacrum in process of union

Sacrum in process of union

Formed femur with femoral attached to Formed femur with attachment to the Formed femur with attachment to the the acetabulum acetabulum acetabulum

Adequate mineralization of the diaphysis Adequate mineralization of the diaphysis Adequate mineralization of the diaphysis Physeal plates are clearly differentiated Physeal plates are not clearly differentiated Physeal plates are not clearly differentiated Irregular femoral condyles

Largely unmineralized with patchy areas Unmineralized with cartilaginous Only skin covering is observable: no of bone formation composition mineralization and cartilaginous tissue present

Well-formed and largely bent/curved Well-formed and largely bent/curved Well-formed and largely bent/curved fibula fibula.

Fragmentation on the fibula

Fibula head appears mineralized

fibula

Fragmentation on the fibula

Fibula head appears mineralized
Partial mineralization 
(Chi-square value $1.448, P$ value 0.485 ).

The degree of soft palate development shows highly significant differences between exposed and unexposed foetuses with a Chisquare value of 9.497 at probability value 0.009 (Table 2).

Development delay was assessed between intrauterine exposed and control groups within head, pelvis and limb regions by evaluating the degree of development in the bones using Chi-square tests. The development of bones in both head and limbs exhibits high significant differences in the degree of development in the foetal skeleton of the exposed group compared to control foetuses and the Chi-square values for head and limb regions are 22.588, 38.297, respectively with $P$ value 0.000 .

Crookedness/Malformation/Tortuous of thorax bones are recorded within the exposed foetuses' skeletons compared to the control ones and are significantly higher for both RF groups than the control (Chisquare value $13.300, P$ value 0.001 ). While, the limb bones showed no differences between experimental groups (Chi-square value $0.464, P$ value 0.793 ).

Osteochondral line development in thorax, pelvis and limbs regions were evaluated and exhibited a significant increase in length of osteochondral lines in ribs and pelvis bones of the foetal skeleton of the exposure group compared to the control ones ( $P$ value 0.000 , 0.016 , respectively). While, limb bones did not show any differences ( $P$ value 0.597 ) (Table 3 ).

Well curving of the bones in thoracic and limb regions had no significant difference between experimental and control groups ( $P$ value $0.306,0.292$ respectively). Furthermore, absence of bones in head and thorax regions did not exhibit any differences in RF exposure groups compared to the control ones ( $P$ value $0.216,0.241$, respectively).

Distinct proximal epiphyseal plate margin in humerus, radius, ulna and femur showed significant differences in differentiation within both exposure groups compared to the control ones, and varied between indistinct proximal epiphyseal to slightly discernible epiphyseal plate, and in some samples there were fragmentations in some parts of long bones such as the radius. In femur, physeal plates are not clearly differentiated in both exposure groups compared to control skeleton samples $(P$ value 0.000$)$ (Table 4$)$

Conformation of long bones of the limbs showed insignificant variations between both $\mathrm{RF}$ groups and the control group $(P$ value

Table 2

Effect of RF-EMF on skeletal development (part 1).

\begin{tabular}{|c|c|c|c|c|c|c|c|c|c|c|c|c|c|c|c|c|c|c|c|c|c|c|c|c|}
\hline \multirow{3}{*}{ Groups } & \multicolumn{12}{|c|}{ Mineralization } & \multicolumn{9}{|c|}{ Fragmentation } & \multirow{2}{*}{\multicolumn{3}{|c|}{$\begin{array}{c}\text { Soft palate development } \\
\text { Head } \\
\end{array}$}} \\
\hline & \multicolumn{3}{|c|}{ Head } & \multicolumn{3}{|c|}{ Thorax } & \multicolumn{3}{|c|}{ Pelvis } & \multicolumn{3}{|c|}{ Linbs } & \multicolumn{3}{|c|}{ Head } & \multicolumn{3}{|c|}{ Pelvis } & \multicolumn{3}{|c|}{ Linbs } & & & \\
\hline & $\begin{array}{l}\text { Rate } \\
(\%)\end{array}$ & Chi & $P$ & $\begin{array}{l}\text { Rate } \\
(\%)\end{array}$ & Chi & $P$ & $\begin{array}{l}\text { Rate } \\
(\%)\end{array}$ & Chi & $P$ & $\begin{array}{l}\text { Rate } \\
(\%)\end{array}$ & Chi & $P$ & $\begin{array}{l}\text { Rate } \\
(\%)\end{array}$ & Chi & $P$ & $\begin{array}{l}\text { Rate } \\
(\%)\end{array}$ & Chi & $P$ & $\begin{array}{l}\text { Rate } \\
(\%)\end{array}$ & Chi & $P$ & $\begin{array}{l}\text { Rate } \\
(\%)\end{array}$ & Chi & $P$ \\
\hline Control & 87 & & & 91 & & & 94 & & & 84 & & & 2 & & & 0 & & & 2 & & & 92 & & \\
\hline $\begin{array}{l}1 \mathrm{~h} / \text { day } \\
\text { exposure }\end{array}$ & 81 & 7.999 & 0.018 & 86 & 1.229 & 0.541 & 90 & 1.709 & 0.425 & 25 & 7.032 & 0.030 & 3 & 1.448 & 0.485 & 15 & 18.999 & 0.000 & 25 & 27.971 & 0.000 & 81 & 9.497 & 0.009 \\
\hline $\begin{array}{l}2 \mathrm{~h} / \text { day } \\
\text { exposure }\end{array}$ & 76 & & & 88 & & & 89 & & & 29 & & & 5 & & & 18 & & & 29 & & & 76 & & \\
\hline
\end{tabular}

Table 3

Effect of RF-EMF on skeletal development (part 2).

\begin{tabular}{|c|c|c|c|c|c|c|c|c|c|c|c|c|c|c|c|c|c|c|c|c|c|c|c|c|}
\hline \multirow{3}{*}{ Grolups } & \multicolumn{9}{|c|}{ Development delayed } & \multicolumn{6}{|c|}{ Crookedness/Malformation/Tortuous } & \multicolumn{9}{|c|}{ Osteochondral lines development } \\
\hline & \multicolumn{3}{|c|}{ Head } & \multicolumn{3}{|c|}{$\begin{array}{c}\text { Pelvis } \\
\end{array}$} & \multicolumn{3}{|c|}{ Linbs } & \multicolumn{3}{|c|}{ Thorax } & \multicolumn{3}{|c|}{ Limbs } & \multicolumn{3}{|c|}{ Thorax } & \multicolumn{3}{|c|}{ Pelvis } & \multicolumn{3}{|c|}{ Limbs } \\
\hline & $\begin{array}{l}\text { Rate } \\
(\%)\end{array}$ & Chi & $P$ & $\begin{array}{l}\text { Rate } \\
(\%)\end{array}$ & Chi & $P$ & $\begin{array}{l}\text { Rate } \\
(\%)\end{array}$ & Chi & $P$ & $\begin{array}{l}\text { Rate } \\
(\%)\end{array}$ & Chi & $P$ & $\begin{array}{l}\text { Rate } \\
(\%)\end{array}$ & Chi & $P$ & $\begin{array}{l}\text { Rate } \\
(\%)\end{array}$ & Chi & $P$ & $\begin{array}{l}\text { Rate } \\
(\%)\end{array}$ & Chi & $P$ & $\begin{array}{l}\text { Rate } \\
(\%)\end{array}$ & Chi & $P$ \\
\hline Control & 10 & & & 0 & & & 5 & & & 5 & & & 11 & & & 10 & 19.533 & 0.000 & 14 & & & 12 & & \\
\hline $\begin{array}{l}1 \mathrm{~h} / \text { day } \\
\text { exposure }\end{array}$ & 34 & 22.588 & 0.000 & 1 & 2.007 & 0.367 & 36 & 38.297 & 0.000 & 18 & 13.300 & 0.001 & 13 & 0.464 & 0.793 & 35 & & & 23 & 8.253 & 0.016 & 14 & 1.032 & 0.597 \\
\hline $\begin{array}{l}2 \mathrm{~h} / \text { day } \\
\text { exposure }\end{array}$ & 37 & & & 0 & & & 41 & & & 28 & & & 10 & & & 32 & & & 31 & & & 17 & & \\
\hline
\end{tabular}
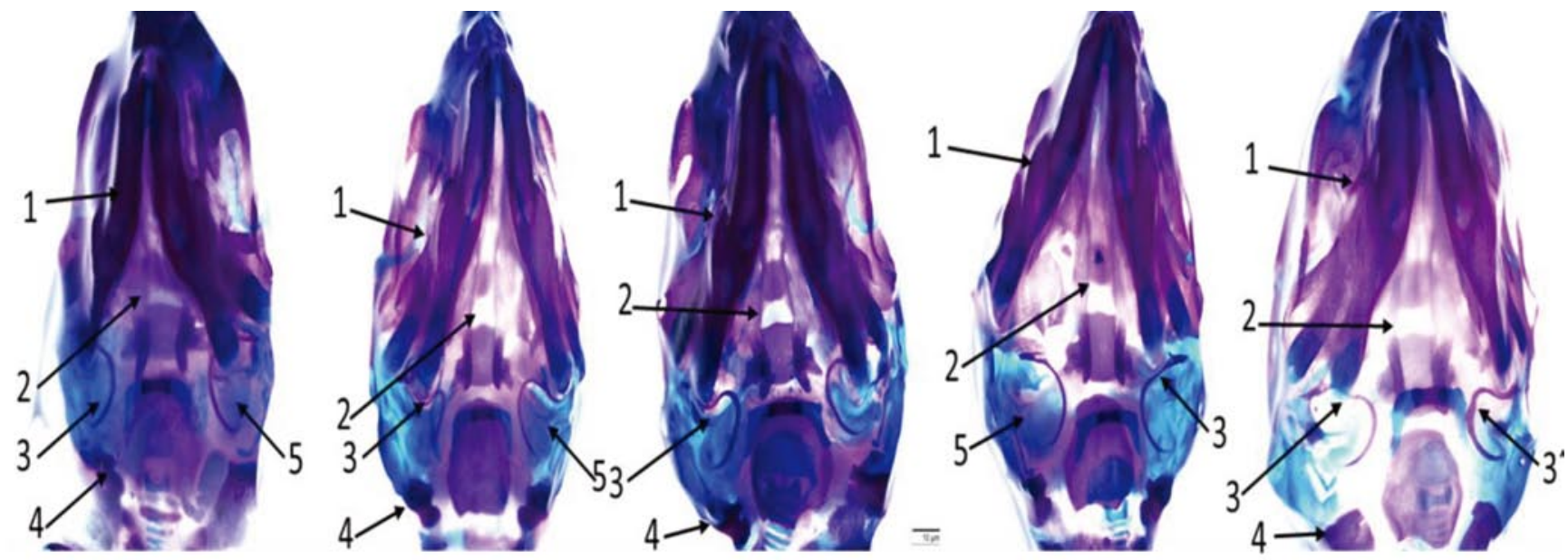

Figure 2. Ventral view of craniums.

(A) Control cranium showing well-formed (1) mandible, (2) cleft palate, (3) tympanic, (4) exoccipital and (5) tympanic bulla bones. (B, C) 1h/day exposure craniums and (D, E) 2h/day exposure craniums revealed less ossification in some parts of skull bones, fragmentation in mandible (1), incomplete cleft palate (2), un-uniformity in the tympanic with thin and abnormal shape $\left(3,3^{\prime}\right)$, defective shape of exoccipital bone and less mineralization in tympanic bulla $(5)$ in photo (E). 
Table 4

Effect of RF-EMF on skeletal development (part 3).

\begin{tabular}{|c|c|c|c|c|c|c|c|c|c|c|c|c|}
\hline \multirow{3}{*}{ Grolups } & \multicolumn{6}{|c|}{ Curving of the bone } & \multirow{2}{*}{\multicolumn{3}{|c|}{$\begin{array}{c}\text { Absence of bones } \\
\text { Pelvis } \\
\end{array}$}} & \multirow{2}{*}{\multicolumn{3}{|c|}{$\begin{array}{c}\text { Distinct proximal epiphyseal plate } \\
\text { Limbs } \\
\end{array}$}} \\
\hline & \multicolumn{3}{|c|}{ Thorax } & \multicolumn{3}{|c|}{ Limbs } & & & & & & \\
\hline & Rate $(\%)$ & Chi & $P$ & Rate $(\%)$ & Chi & $P$ & Rate $(\%)$ & Chi & $P$ & Rate $(\%)$ & Chi & $P$ \\
\hline Control group & 94 & & & 92 & & & 0 & & & 0 & & \\
\hline $1 \mathrm{~h} /$ day exposure & 88 & 2.367 & 0.306 & 87 & 2.462 & 0.292 & 3 & 2.847 & 0.241 & 18 & 22.812 & 0.000 \\
\hline $2 \mathrm{~h} /$ day exposure & 89 & & & 85 & & & 2 & & & 21 & & \\
\hline
\end{tabular}

0.229). Indentations on the skull of intrauterine exposed foetuses showed no differences within all experimented groups ( $P$ value 0.229) (Table 5).

Table 5

Effect of RF-EMF on skeletal development (part 4).

\begin{tabular}{|c|c|c|c|c|c|c|}
\hline \multirow{3}{*}{ Grolups } & \multicolumn{3}{|c|}{ Conformation of the bone } & \multicolumn{3}{|c|}{ Indentation on the skull } \\
\hline & \multicolumn{3}{|c|}{ Limbs } & \multicolumn{3}{|c|}{ Head } \\
\hline & $\operatorname{Rate}(\%)$ & Chi & $P$ & $\operatorname{Rate}(\%)$ & Chi & $P$ \\
\hline Control & 93 & & & 4 & & \\
\hline $1 \mathrm{~h} /$ day exposure & 98 & 2.947 & 0.229 & 3 & 2.947 & 0.229 \\
\hline $2 \mathrm{~h} /$ day exposure & 94 & & & 8 & & \\
\hline
\end{tabular}

\subsection{Morphological study of embryonic skeletal development} under dissecting microscope

Examination of the foetal skeleton under a dissecting microscope revealed that intrauterine RF exposure led to some detrimental defects in bone formation and development cranium skeletal samples show less ossification, increase cartilage rate, fragmentation in mandibular bone with anomalies in premaxilla mandibular bones in both exposure groups compared to the control ones. Figure 1. Incomplete differentiation of soft palate and un-uniformity in tympanic ones with irregular shape of exoccipital bones as well as remarkable mineralization of the tympanic bulla were recorded in craniums of RF groups with malformation and less mineralization of occipital joint and interparietal (Figure 2, 3).

Examination of thoracic region for malformation or /and development delay revealed that the RF exposure group showed irregular borders of the ribs with an un-uniform shape and demineralization in some ribs in addition to ossification retardation at the costochondral junction. Furthermore, there was deformity in the upper part of ribs 4-8 (Figure 4).

GSM-like signals in-utero exposure for $20 \mathrm{~d}$ affected the differentiation and development of coccygeal vertebrae negatively, leading to short tails as well as deformity in some coccygeal vertebrae leading to bent tail compared to normal tails in the control group. Stubby and short tails coupled with complete absence of coccygeal bones throughout the length of the tail from the 7 th coccyx of $2 \mathrm{~h} /$ day intrauterine exposure compared to the control group (Figure 5).

\section{Discussion}

Differences in foetal skeleton formation and development between $\mathrm{RF}$ exposure groups and the control group were noticed to investigate the teratogenic effect of $1800 \mathrm{MHz}$ GSM-like signals on embryonic development. The study findings revealed that these GSM signals lead to some detrimental effects on foetal skeleton formation and differentiation in various parts of the foetal skeleton. For instance, the cranium shows malformation in soft palate, lack ossification in frontal and parietal bones, deformity in the tympanic bone and immature formation of occipital joints. Furthermore, the pelvis, ribs and limbs show malformation, fragmentation, lack of ossification and absence of coccygeal vertebrae with deformity in some parts of the coccygeal vertebrae. This is consistent with previous studies[21], who found that the low-frequency magnetic fields cause lesser skeletal anomalies. The incidence of minor variations in skeletal development, including reduction of skeletal calcification and loss of a skeleton may be revealed and enhanced in combination with a teratogenic agent[22].

Furthermore, mild exposure to mobile phone radiation may effect mouse foetal development at the ossification level due to interference of EMFs with normal mammalian embryonic development[10], Skeletal system abnormalities including short and curved tails, absence of 13th rib, ad wavy ribs, and absence of the caudal vertebrae were recorded in rat foetuses in the $30 \mathrm{~min}$ in-utero mobile phone irradiation group[9]. Consistently with our results[23] found that $900 \mathrm{MH}$ mobile phone radiation altered the concentration of osteogenesis and bone resorption markers in rats. These changes change the mechanical characteristic features of long bones and L4 vertebra and lower the content of calcium of these bones through indirect pathways of calcium mobilization. Another study in line with our findings[24], shows that both static and $50 \mathrm{~Hz}$ electric fields influence the early development of rat bones. Siddiqi, C, Norrish, \& Heming, 2016, found that mobile phone radiation exposure during the incubation period of chicken eggs leads to some detrimental effects on growth development.

The study results conflict with[25,26], who discovered that prenatal exposure of rats to $915-\mathrm{MHz}$ microwave radiation did not induce or exhibit teratogenic effects on the foetal skeleton. Nishimura et al.[27] found that exposure to intermediate frequency $(300 \mathrm{~Hz}-100 \mathrm{KHz})$ magnetic fields during embryogenesis showed no teratogenic effect under experimental conditions.

Foci of ossification when starting configuration in the normal bone development, the chondrocytes become enlarged and their cytoplasm vacuolated. Due to the hypertrophy of chondrocytes and the enlargement of their lacunae in the cartilage matrix will gradually reduce the thin irregular and fenestrated septa, and the remaining hyaline matrix will be calcified. These parts of the skeleton will stain neither Alcian blue nor Alizarin red in the calcified centres of normal foetuses which may correspond to the vacuolated cytoplasm of chondrocytes or their enlarged lacunae. RF exposed foetuses showed large and irregular unstained portions compared to normal foetuses.

Our data indicate that RF-EMF inhibits bone deposition when the primary ossification centres are being formed during embryogenesis through the interaction of the electromagnetic radiation with vital molecules and ions being involved in foetal growth. The RF signals alter the processes of bone mineralization and the intensity of bone 

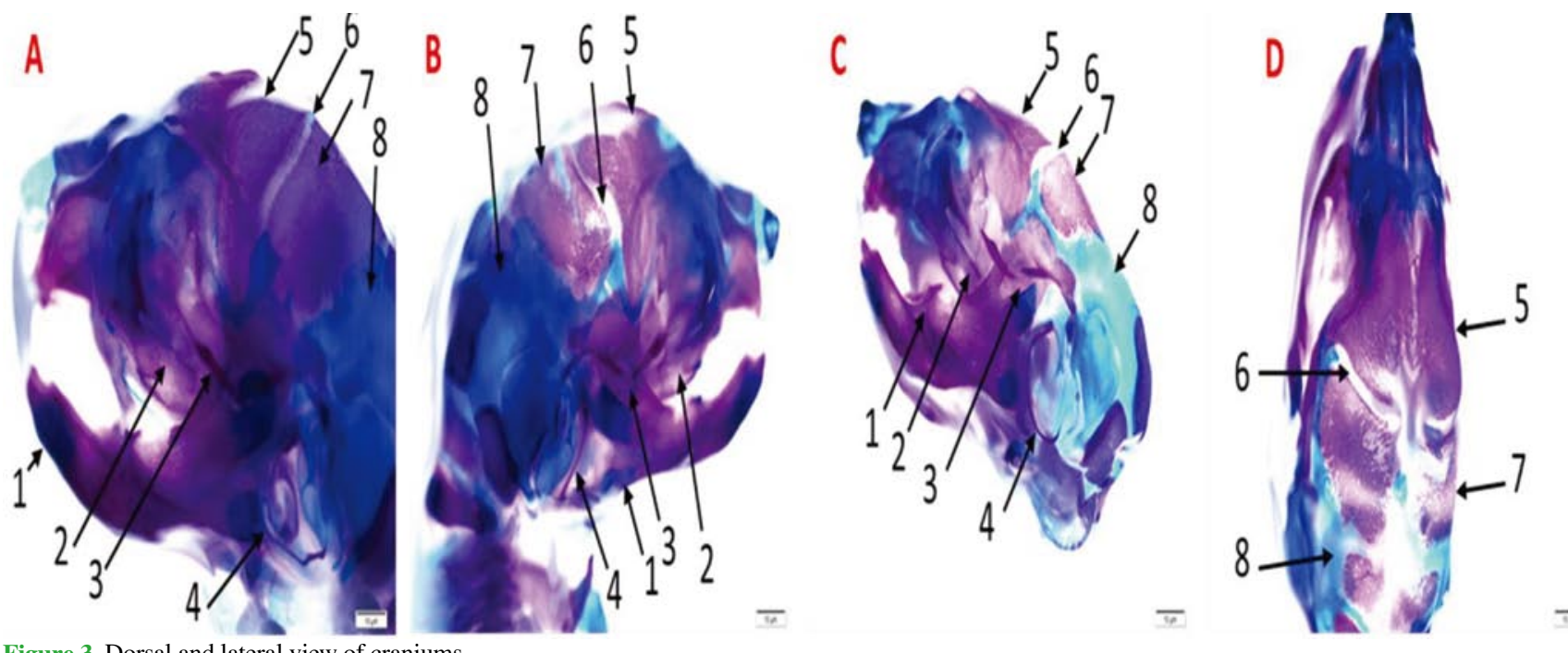

(A) Well-formed cranium in control skull sample showing normal ossification of (1) mandible, (2) palatine, (3) zygomatic, (4) tympanic, (5) frontal, (6) occipital joint, (7) parietal and (8) interparietal bones. (B, C, D) Craniums of RF groups showing fragmentation in (1) mandible, (3) zygomatic. Deformity in tympanic bones (4) in photos (B, C), less ossification in parietal and frontal bones $(5,7)$ with malformation and less mineralization of occipital joint (6) in photos (B, C, D). Incomplete ossification of interparietal.
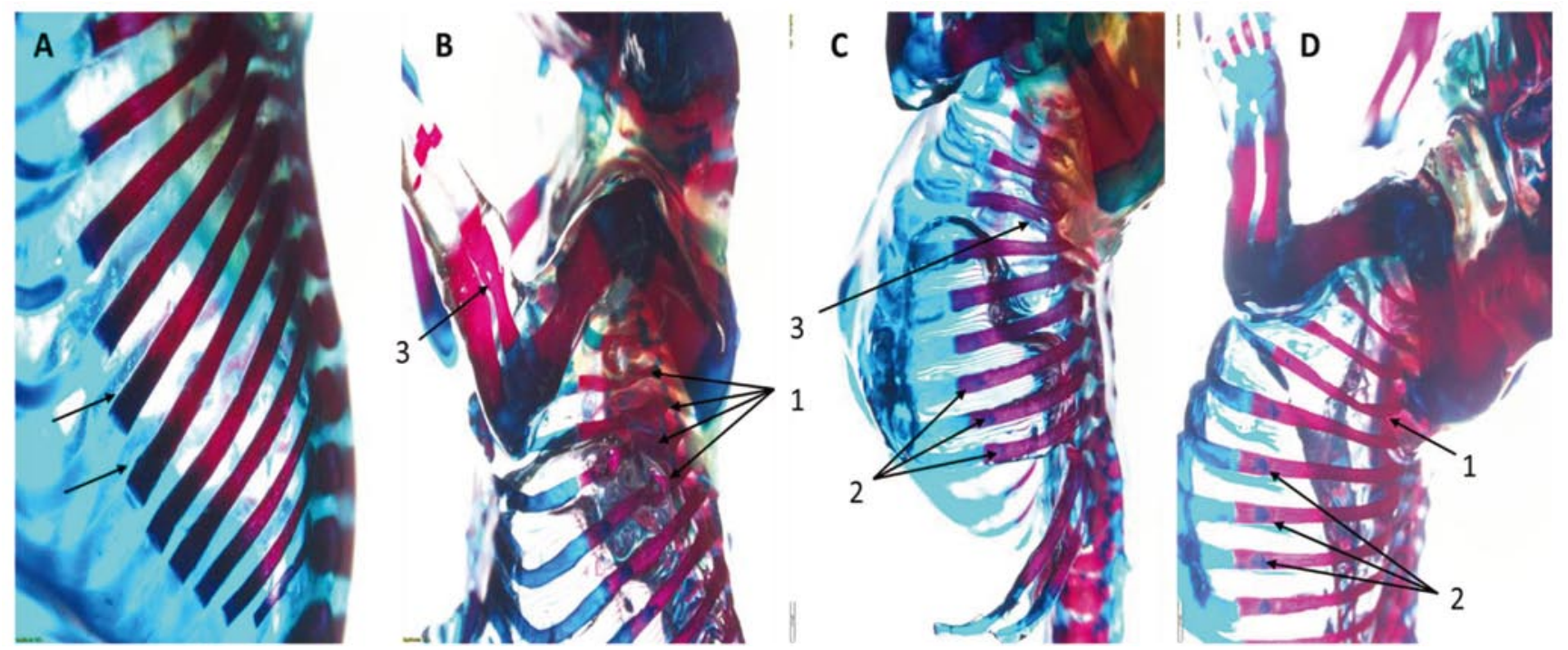

Wigure 4. Left view of thorax region. retardation at costochondral junction (2). Furthermore, fragmentation was recorded in some ribs and radius (3) photos (B, C, D).

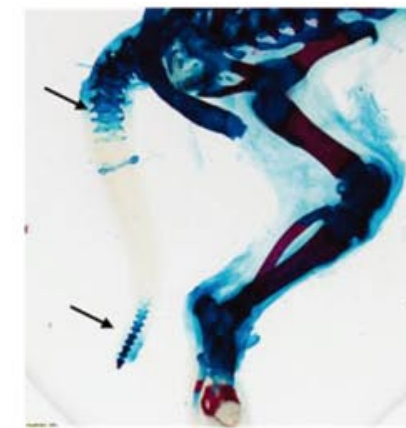

D

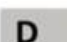

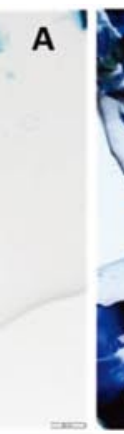

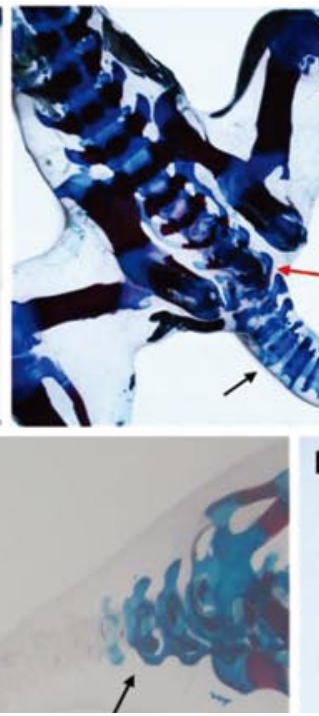

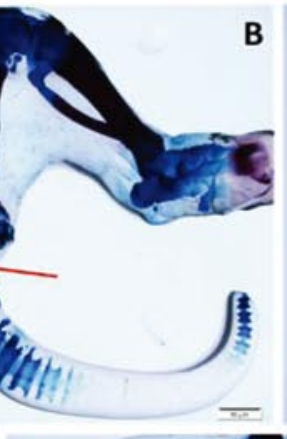

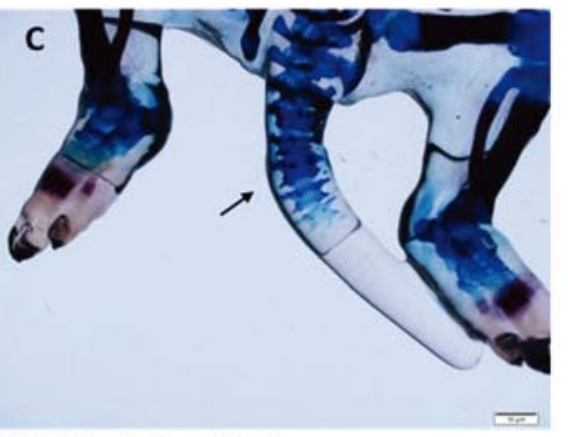

$\mathbf{E}$
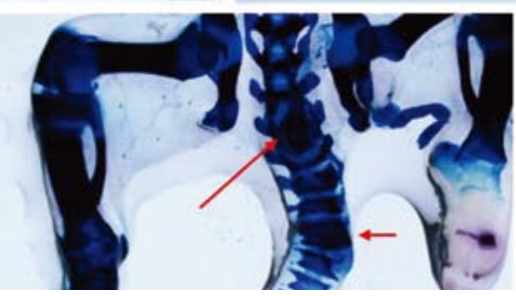

Figure 5. Ventral view of pelvic region.

(A) Well-formed tail at GD 20 in control group sample showing normal ossification of coccygeal vertebrae indicated by arrows. (B, C) RF group for $1 \mathrm{~h} /$ day show deformity in second coccygeal vertebrae indicated by red arrow and short tail with immature vertebrae was recorded. (D, E) $2 \mathrm{~h} / \mathrm{day}$ exposure group showing short tail with absence of some coccygeal vertebrae and lack of ossification indicated by black arrow. 2nd, 3rd and 7th coccygeal vertebrae showing deformity in their development indicated by red arrows. 
turnover processes, and thus impact embryonic skeleton formation and development directly.

\section{Conflict of interest statement}

We declare that we have no conflict of interest.

\section{Acknowledgements}

The project was fully supported by Faculty of Veterinary Medicine of Universiti Malaysia Kelantan. The authors are indebted to anatomy specialist Prof. Dr. Zahirul Islam and the radiologist Dr. Ibrahim Aziz. Also I would like to thanks all research assistants at the radiology unit for their help.

\section{References}

[1] Foster R, Kenneth R, Glaser R. Thermal mechanisms of interaction of radiofrequency energy with biological systems with relevance to exposure guidelines. Heal Phys 2007;92: 609-620.

[2] McNamee JP, Chauhan V. Radiofrequency radiation and gene/protein expression: A review. Radiat Res 2009; 172: 265-287.

[3] Nylund R. Proteomics analysis of human endothelial cells after short-term exposure to mobile phone radiation. Ph.D [Thesis]. Radiation and Nuclear Safety Authority, Aalto University School of Science; 2011.

[4] Guler G, Tomruk A, Ozgurn E, Seyhan N. The effect of radiofrequency radiation on DNA and lipid damage in non-pregnant and pregnant rabbits and their newborns. Gen Physiol Biophys 2010; 29(1): 59-66.

[5] World Health Organization. WHO research agenda for radiofrequency fields. Bioelectromagnetics 2011: 32(5): 417-421.

[6] Berman E, Carter HB, House D. Observations of rat fetuses after irradiation with 2450-MHz (CW) microwaves. J Microw Power 1981; 16: 9-13.

[7] Lary JM, Conover DL, Foley ED, Hanser PL. Teratogenic effects of 27.12 MHz radiofrequency radiation in rats. Teratology 1982; 26: 299309.

[8] Ingole I, Ghosh S. Cell phone radiation and developing tissues in chick embryo - a light microsopic study of kidneys. J Anat Soc India 2006; 55: 19-23.

[9] Ashraf El-Sayed AMK, Hoda S Badr, Rania Yehia, Salem M Salem, Asmaa M Kandil. Effects of thirty minute mobile phone irradiation on morphological and physiological parameters and gene expression in pregnant rats and their fetuses. Afr J Biotechnol 2011; 10(26): 1967019680.

[10]Fragopoulou AF, Koussoulakos SL, Margaritis LH, Cranial and postcranial skeletal variations induced in mouse embryos by mobile phone radiation. Pathophysiology 2010; 17: 169-177.

[11]Al-Qudsi F. Effect of electromagnetic mobile radiation on chick embryo development. Life Sci J 2012; 9: 983-991.

[12]Amer FI, El Shabaka HA, Zakaria I, Mohammed HA, Effect of microwave radiation on the retina of mice embryos. J Biol Life Sci 2013; 4: 215-231.

[13]Aldad TS, Gan G, Gao XB, Taylor HS. Fetal radiofrequency radiation exposure from 800-1 $900 \mathrm{mhz}$-rated cellular telephones affects neurodevelopment and behavior in mice. Sci Rep 2012; 2: 1-7.

[14]Sambucci M, Laudisi F, Nasta F, Pinto R, Lodato R, Altavista P, et al. Prenatal exposure to non-ionizing radiation: effects of wifi signals on pregnancy outcome, peripheral b-cell compartment and antibody production. Radiat Res 2010; 174: 732-740.

[15]Poulletier de Gannes F, Billaudel B, Haro E, Taxile M, Le Montagner L, Hurtier A, et al. Rat fertility and embryo fetal development: Influence of exposure to the Wi-Fi signal. Reprod Toxicol 2013; 36: 1-5.

[16]Kismali G, Ozgur E, Guler G, Akcay A, Sel T, Seyhan N. The influence of $1800 \mathrm{MHz}$ GSM-like signals on blood chemistry and oxidative stress in non-pregnant and pregnant rabbits. Int J Radiat Biol 2012; 88: 414-419.

[17]Ozgur E, Kismali G, Guler G, Akcay A, Ozkurt G, Sel T, et al, Effects of prenatal and postnatal exposure to GSM-like radiofrequency on blood chemistry and oxidative stress in infant rabbits, an experimental study. Cell Biochem Biophys 2013; 67: 743-751.

[18]Tomruk A, Guler G, Dincel AS. The influence of 1800 MHz GSM-like signals on hepatic oxidative DNA and lipid damage in non pregnant, pregnant, and newly born rabbits. Cell Biochem Biophys 2010; 56: 39-47.

[19]Erdo an DPT, Kadio lu D. Visualsation of the skeletal system by double staining with alizarin red and alcian blue. Gazi Med J 1995; 6: 55-58.

[20]Trueman D, Jackson SW, Trueman B. An automated technique for double staining rat and rabbit fetal skeletal specimens to differentiate bone and cartilage, biotech. Histochem 2009; 74: 98-104.

[21]Huuskonen H, Juutilainen J, Komulainen H. Effects of low-frequency magnetic fields on fetal development in rats. Bioelectromagnetics 1993; 14: 205-213.

[22]Chiang H, Wu RY, Shao BJ, Fu YD, Yao GD, Lu DJ. Pulsed magnetic field from video display terminals enhances teratogenic effects of cytosine arabinoside in mice. Bioelectromagnetics 1995; 16(1): 70-74.

[23]Siero-Stołtny A, Teister K, Cie lar Ł, Siero G, Liwinski D, Kucharzewsk $\mathrm{Z}$, et al. The influence of electromagnetic radiation generated by a mobile phone on the skeletal system of rats. Biomed Res Int 2015; 11. doi:10.1155/2015/896019.

[24]Okudan B, Keskin AÜ, Aydın MA, Cesur G, Çömlekçi S, Süslü H, DEXA analysis on the bones of rats exposed in utero and neonatally to static and $50 \mathrm{~Hz}$ electric fields, Bioelectromagnetics. 2006; 27: 589-592.

[25]Jensh RP, Weinberg I, Brent RL, Teratologic studies of prenatal exposure of rats to 915-MHz microwave radiation. Radiat Res 1982; 92: 160-171.

[26]Ogawa K, Nabae K, Wang J, Wake K, Watanabe S, Kawabe M, et al. Effects of gestational exposure to $1.95-\mathrm{GHz}$ W-CDMA signals for IMT2000 cellular phones: Lack of embryotoxicity and teratogenicity in rats. Bioelectromagnetics 2009; 30: 205-212.

[27]Nishimura I, Oshima A, Shibuya K, Negishi T. Lack of teratological effects in rats exposed to 20 or $60 \mathrm{kHz}$ magnetic fields. Birth Defects Res Part B Dev Reprod Toxicol 2011; 92: 469-477. 